\title{
Provérbios e publicidade: percursos discursivos de sentido
}

\author{
Proverbs and advertising: discursive paths of meaning
}

Refranes y publicidad: caminos discursivos de significado

\author{
Anita Luisa Fregonesi de Moraes ${ }^{1}$ (iD https://orcid.org/0000-0003-2529-7704
}

\begin{abstract}
RESUMO: Este artigo visa analisar como se constituem os sentidos dos enunciados proverbiais inseridos em textos publicitários. Para fundamentar nossas análises, articulamos a teoria enunciativo-discursiva de Maingueneau e a perspectiva dialógica da linguagem proposta por Bakhtin que permitem descrever os fatos da língua verificados no fio discursivo de textos publicitários e compreender os efeitos de sentido produzidos pelo cruzamento do interdiscurso com o intradiscurso por meio do trabalho da memória. Considerando ainda que, de acordo com a Análise do Discurso, os processos que constituem a linguagem são histórico-sociais, e o discurso, conforme Orlandi (1999), é um "efeito de sentido entre interlocutores", verificamos que os enunciados proverbiais, apesar de serem considerados típicos da oralidade e da cultura popular, são usados pela mídia propagandística escrita, que tem como alvo um público letrado visto como consumidor em potencial. Nossas análises evidenciam que os provérbios, subvertidos ou não em seu sentido original e em sua materialidade linguística, participam como estratégias discursivas de convencimento, pois transmitem a voz do povo, via mídia impressa. Assim, a reiteração desses enunciados, que representam um arquivo estabilizado, dá lugar para sentidos outros, embora o sujeito enunciador mantenha a ilusão de ser a origem do dizer.
\end{abstract}

PALAVRAS-CHAVE: Provérbios. Publicidade. Efeitos de sentido.

ABSTRACT: This article aims at analyzing how the meanings of proverbial statements in advertising texts are constituted. In order to base it, we articulate Maingueneau's enunciativediscursive theory and the dialogical perspective of language proposed by Bakhtin, which allow both to describe the facts of the language verified in the discourse strand of advertising texts and to understand the effects of meaning produced by the intersection of interdiscourse through the work of memory. Furthermore, considering the fact that, according to the Discourse Analysis, the processes which constitute language are historical-socially founded and, according to Orlandi (1999), speech is a "meaning effect among interlocutors", we find that, despite being considered

\footnotetext{
${ }^{1}$ Doutoranda em Estudos da Linguagem pela Universidade Estadual de Londrina (UEL). Docente no Instituto Federal de São Paulo (IFSP). E-mail: anita.fregonesi@hotmail.com.
} 
typical of orality and originated from popular culture, proverbial statements are widely used by the written advertising media, which targets a literate audience, seen as a potential consumer. Our analyzes show that the proverbs, subverted or not in their original sense and in their linguistic materiality, participate as discursive strategies of persuasion, as the authority of the voice of the people, via printed media. Thus, the reiteration of these statements, which represent a stabilized archive, enables the uses of other meanings, although the enunciating subject maintains the illusion of being the origin of the saying.

KEYWORDS: Proverbs. Advertising. Sense effects.

RESUMEN: Este artículo tiene como objetivo analizar cómo se constituyen los significados de los enunciados proverbiales en textos publicitarios. Para fundamentar nuestros análisis, articulamos la teoría enunciativo-discursiva de Maingueneau y la perspectiva dialógica del lenguaje propuesta por Bakhtin, que permiten describir los hechos del lenguaje verificados en el hilo discursivo de los textos publicitarios y comprender los efectos de significado producidos por la intersección del intradiscurso con el intradiscurso a través del trabajo de la memoria. Considerando que, según el Análisis del Discurso, los procesos que constituyen el lenguaje son histórico-sociales y el discurso, según Orlandi (1999), es un "efecto de significado entre interlocutores", verificamos que los enunciados de los refranes, a pesar de considerados típicos de la oralidad y de la cultura popular, son utilizados por los medios de publicidad escritos, que se dirigen a una audiencia alfabetizada, la cual es vista como consumidora potencial. Nuestros análisis muestran que los refranes, subvertidos o no en su sentido original y en su materialidad lingüística, participan como estrategias discursivas de persuasión, ya que transmiten la autoridad de la voz del pueblo, a través de los medios impresos. Así, la reiteración de estos enunciados, que representan un archivo estabilizado, da paso a otros significados, aunque el sujeto enunciador mantiene la ilusión de ser el origen del dicho.

PALABRAS CLAVE: Refranes. Publicidad. Efectos de significado.

\section{Introdução}

Neste artigo, propomo-nos a analisar discursos publicitários, tendo como objeto propagandas veiculadas na mídia impressa construídas a partir da articulação de provérbios. Analisar discurso não é uma tarefa fácil, dadas as inúmeras definições oriundas de diferentes concepções teóricas; além disso, para se referirem às produções verbais, os linguistas também recorrem aos termos enunciado e texto. Cabe-nos, portanto, precisar a perspectiva teórica abordada nessas análises.

\section{Fundamentação teórica: discurso e ethos}

O termo discurso constitui parte essencial das ciências da linguagem e é empregado tanto no singular, referindo-se à atividade verbal em geral, como no plural, ao se referir a cada evento da fala. Na verdade, esse termo representa uma mudança na maneira de conceber a linguagem ao considerar o texto como unidade primeira, tendo 
como condição a textualidade, a qual, de acordo com a Análise do Discurso (AD), é a "relação do texto consigo mesmo e com a exterioridade" (ORLANDI, 2004, p. 52). É com esse sentido de exterioridade que a perspectiva abordada neste trabalho considera o texto como objeto histórico, resultado de uma atividade subjetiva inscrita em um contexto determinado como parte constitutiva do sentido; ou seja, no discurso, os sentidos são historicamente construídos. A AD, portanto, tem como objeto de estudo o discurso que, por sua vez, se manifesta em textos, concebidos como objetos linguístico-históricos.

Michel Pêcheux (1990) entende o discurso como o lugar da manifestação de uma subjetividade atravessada pela presença do outro. Nesse sentido, a Análise do Discurso traz uma contribuição aos estudos do discurso: qualquer modificação na materialidade linguística, a ordem significante, corresponde a "diferentes gestos de interpretação, compromisso com diferentes posições de sujeito, com diferentes formações discursivas, distintos recortes de memória, distintas relações com a exterioridade" (ORLANDI, 2004, p. 14).

O analista do discurso considera a enunciação como resultado do outro nas sociedades e na história: "é porque há o outro nas sociedades e na história, correspondente a esse outro próprio ao linguageiro discursivo, que aí pode haver ligação, identificação ou transferência" (PÊCHEUX, 1990, p. 54). É nesse viés teórico que este artigo se situa: os efeitos de sentido são construídos na enunciação, no entrelaçamento da materialidade linguística (como se diz, quem diz) com os já-ditos (a história, o ideológico) que se fazem presentes nessa materialidade por meio do trabalho da memória. Para Pêcheux (1990, p. 55), "esse discurso-outro, enquanto presença virtual na materialidade descritível da sequência, marca [...] a insistência do outro como lei do espaço social e da memória histórica".

$\mathrm{O}$ aprofundamento da teoria do discurso no que se refere à subjetividade, à historicidade e às redes de memória faz-nos pensar nos enunciados proverbiais em um contexto mais específico, o de como se constituem os efeitos de sentido no discurso, especificamente no discurso publicitário ${ }^{2}$, considerado altamente persuasivo, oferecendo um mundo colorido de abundância, progresso e felicidade. Em decorrência disso, a mensagem é manipulada de modo que, ao discurso de apresentação do objeto desejado,

\footnotetext{
2 O termo discurso toma um valor mais preciso, sendo considerado "um uso restrito" da língua, definida como um sistema compartilhado pelos membros de uma comunidade linguística. Nesse sentido, discurso publicitário é um "tipo de discurso" (CHARAUDEAU; MAINGUENEAU, 2002, p.186).
} 
sobrepõe-se um discurso de representação dos "sujeitos desejantes" (LANDOWSKI, 1992, p. 105). Assim, o discurso publicitário oferece as imagens que valorizam o produto e, ao mesmo tempo, constitui a identidade do seu público, oferecendo a suposta imagem de seu desejo, utilizando para tanto todos os recursos disponíveis dos códigos linguístico e não linguístico.

Tais considerações estão estreitamente relacionadas aos participantes do evento discursivo, uma vez que, nesse espaço, surgem imagens que não são dos enunciadores, mas pertencentes ao próprio discurso, ou seja, o fenômeno discursivo está atrelado à enunciação e, por meio dela, a personalidade do enunciador é revelada. A esse tipo de fenômeno, um desdobramento da retórica tradicional é válido para qualquer discurso, dá-se o nome de ethos, o qual, segundo Maingueneau (2005, p. 98, grifo do autor), define-se por "um tom que dá autoridade ao que é dito. Esse tom permite ao leitor construir uma representação do corpo do enunciador [...] [fazendo] emergir uma instância subjetiva que desempenha o papel de fiador do que é dito", manifestando seu modo de ser e envolvendo a enunciação, mas sem estar explícito no enunciado. Esse traço enunciativo, portanto, confere ao enunciador uma identidade compatível com o mundo que ele deseja construir em seu enunciado e cujas representações constituem estereótipos culturais que circulam nos domínios mais diversos: publicidade, cinema, literatura, etc.

Nesse movimento, o enunciador, ao assumir dada posição discursiva, confere características, tais como ritmo, escolha de palavras, direção argumentativa, entre outras que levam o coenunciador a conferir um ethos ao seu fiador, aderindo ao discurso que está sendo proferido e permitindo a constituição de uma comunidade que comunga do mesmo discurso, o que determina, portanto, a ação do ethos sobre o coenunciador; a esse fato, Maingueneau (2005) chama de "incorporação". Portanto, na concepção discursiva de ethos, é o posicionamento do enunciador que definirá seu modo de enunciação, ou melhor, seu ethos.

A partir dessas observações, podemos dizer que o ethos discursivo vai se engendrando na enunciação, legitimando-se para a construção da cena enunciativa, isso porque ele tem um lugar específico de circulação, o discurso e segundo Maingueneau (2005, p. 87) "todo discurso, por sua manifestação mesma, pretende convencer instituindo a cena de enunciação que o legitima", ou seja, a encenação de um discurso 
são as pistas deixadas por um enunciador que toma a palavra e, a partir dela, o legitima e valida o seu dizer. Entretanto, adverte o autor, a cenografia não é apenas um cenário para o discurso, mas "é a enunciação que, ao se desenvolver, esforça-se para constituir progressivamente o seu próprio dispositivo de fala" (MAINGUENEAU, 2005, p. 87).

A cena enunciativa, portanto, trata-se de um "espaço instituído, definido pelo gênero de discurso, mas também sobre a dimensão constitutiva do discurso, que se 'coloca em cena', instaura seu próprio espaço de enunciação" (CHARAUDEAU; MAINGUENEAU, 2002, p. 515, grifo do autor). Desse modo, o discurso implica um enunciador e um coenunciador, um espaço e tempo da enunciação que validam a própria instância, permitindo sua existência. Em termos de discurso, tanto o enunciador quanto o coeneunciador dispõem de um lugar no qual o enunciador projeta uma imagem de si no discurso a partir da qual o legitima. Assim, enunciador e coenunciador estão relacionados à cena de enunciação, o primeiro demarcando seu posicionamento e validando seu dizer por meio de um ethos envolvente cujo poder de persuasão leva o destinatário a participar do mundo configurado na enunciação e a identificar-se com o movimento de um corpo investido de valores historicamente declarados.

\section{O discurso proverbial}

Especificamente no caso de enunciados proverbiais usados nos textos publicitários, recorremos a Obelkevich (1997, p. 45), para quem, tradicionalmente, os provérbios são "estratégias para situações, mas estratégias com autoridade, que formulam uma parte do bom senso de uma sociedade, seus valores e a maneira de fazer as coisas". Para o autor, o que define o provérbio não é a sua estrutura linguística, mas a função externa, normalmente moral e didática: as pessoas utilizam-no para dizer às outras que atitude tomar em relação a determinada situação. Assim entendemos a expressão bom senso utilizada por Obelkevich (1997).

Essa característica assume o estatuto de um "discurso constituinte" (MAINGUENEAU, 2006), aqueles que dão sentido aos atos da coletividade, zonas de falas em meio a outras falas as quais se pretendem sobrepor. Por outro lado, cuidamos que a cenografia implica o uso da linguagem, um investimento em um código linguageiro que permite produzir um efeito prescritivo que resulta de uma conveniência entre a linguagem e o sentido do texto. Assim, as formas enunciativas, por possuírem um caráter 
constituinte, conferem uma autoridade particular aos enunciados, permitindo-lhes uma "inscrição", ou seja, elas seguem "os traços de um Outro invisível, que associa os enunciadores-modelo de seu posicionamento e, no limite, a presença daquela Fonte que funda o discurso constituinte: a Tradição, a Verdade, a Beleza..." (MAINGUENEAU, 2006, p. 43).

Vislumbramos o uso dos provérbios nos textos publicitários como uma das estratégias de persuasão, utilizando a voz do senso comum, da comunidade, que fala por intermédio deles. Dessa maneira, procuramos mostrar que diferentes vozes, trazidas pela memória discursiva, entrecruzam-se nesses enunciados e que é no encontro dessas vozes com a voz do "emissor-anunciante" (LANDOWSKI, 1992, p. 104), em posição de enunciador, que se constitui o sentido.

Os provérbios representam um tipo relativamente estável de enunciado, numa perspectiva estilística, composicional e, muitas vezes, temática. Isso nos faz considerálos, de acordo com Bakhtin (1992), pertencentes a um gênero do discurso.Os gêneros, sob a perspectiva bakhtiniana, são práticas sociocomunicativas construídas historicamente por fenômenos sociais e dependentes da situação comunicativa em que são enunciados. Eles são determinados pela esfera discursiva e estão presentes em toda atividade comunicativa humana, representando as formas de dizer e de interagir em cada situação específica e refletindo "de modo mais imediato, preciso e flexível todas as mudanças que transcorrem na vida social" (BAKHTIN, 2003, p. 268). Os gêneros, portanto, estão intimamente ligados à cultura popular, caracterizada como uma atividade resistente a uma "rede de forças e de representações estabelecidas" (DE CERTEAU, 2005, p. 79), alternando as regras desse espaço opressor. São enunciados metafóricos, marcados por usos e por uma historicidade social, e que incorporam atitudes populares.

Por serem atemporais e representarem a voz do senso comum, sua enunciação é "fundamentalmente polifônica" (MAINGUENEAU, 2005, p. 169). Proferir um provérbio é dar à voz do enunciador uma outra voz, a voz do bom senso e dos valores de uma sociedade, sem deixar, entretanto, de dar responsabilidade ao enunciador, já que ele faz parte, assim como o provérbio, de uma comunidade. Cabe ao coenunciador reconhecer o provérbio como tal, apoiado em sua memória e na estrutura composicional cristalizada do enunciado.

Na perspectiva da $A D$, os provérbios, vistos como enunciados pertencentes ao 
universo discursivo não estabilizado logicamente, são suscetíveis a tornarem-se outros, de se deslocarem discursivamente de seus sentidos para outros sentidos. Nesse processo, interferem diretamente as condições de produção, que compreendem os sujeitos, a situação e a memória discursiva, isto é, aquilo que já foi dito antes, em outro lugar e que retoma em forma de já-dito. É a memória discursiva, o interdiscurso, que disponibiliza os dizeres que vão determinar o modo como o sujeito produz sentido em uma dada situação enunciativa. Trabalhar com esse gênero discursivo implica trabalhar como sua materialidade discursiva, o real da língua na sua existência simbólica, abordando-a a partir do equívoco, de sua heterogeneidade. Dessa maneira, a enunciação proverbial, vista como estereotipada, torna-se outra no discurso midiático, adquirindo novos sentidos cujos limites são dados pela situação enunciativa.

É nessa perspectiva que delineamos nosso aparato teórico, buscando também reflexões sobre o aspecto enunciativo para podermos articulá-las aos conceitos da $A D$ propostos por Pêcheux. Nossa reflexão parte, portanto, do processo discursivo, considerando o aspecto linguístico para chegar à compreensão de como os sentidos se constituem.

\section{Provérbios em textos publicitários}

Tendo como pressuposto que discurso e quadro social são inseparáveis, compreendemos que a relação entre o enunciado proverbial e o do texto publicitário não é exclusivamente lúdica, pois permite que este construa sua própria identidade. Seguindo essa orientação, pretendemos detectar pontos onde transpareçam as posturas ideológicas que dizem respeito aos interdiscursos que se materializam nesses discursos e os efeitos de sentido que eles emergem. Dessa perspectiva, para este artigo, foram selecionados dois textos publicitários nos quais se busca reconhecer, por meio de marcas discursivas, a construção da sua própria identidade.

Segundo Maingueneau (2005), a utilização consciente de um texto ou de um gênero para compor um discurso outro pode se servir de duas estratégias: a captação e a subversão. Na captação, o sujeito apropria-se de outro enunciado "tomando a mesma direção" (MAINGUENEAU, 2005, p. 173), adaptando seu valor pragmático, ao contrário da subversão, quando o enunciado descaracteriza o texto original. 


\section{Análise 1:}

Um exemplo de um processo de captação foi retirado do jornal Folha de S.Paulo (18 abr 2006, p. A5) e traz o seguinte enunciado: Em abril, um feriado é pouco, dois é bom e três é demais! O hotel Portobello é a melhor opção do mês de abril. Afinal, só aqui você passa os feriados da Semana Santa, de Tiradentes e o do Dia do Trabalho em um resort com praia, safári e fazenda. E o melhor: tudo isso com preços de baixa temporada. Consulte nossos preços e faça sua reserva., que tem como provérbio original Um é pouco, dois é bom, três é demais, o qual apresenta lacunas linguísticas, podendo ser preenchidas na enunciação: Um (?) é pouco, dois (?) é bom, três (?) é demais.

Figura 1: Um é pouco, dois é bom, três é demais.

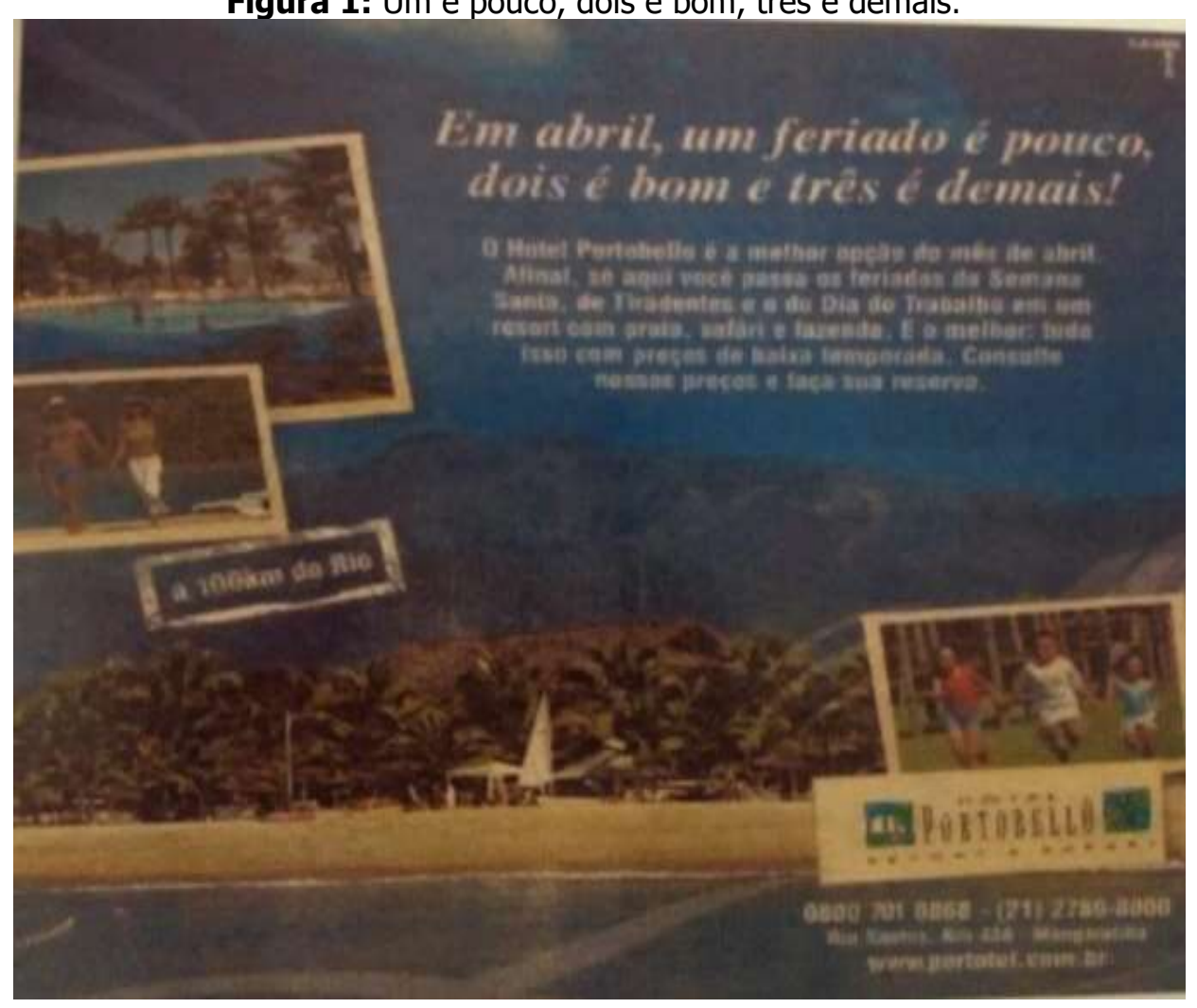

Fonte: Folha de S. Paulo (18 abr 2006)

O enunciador do texto publicitário aproveita-se dessa característica para compor o novo enunciado e pretende divulgar a possibilidade de passar os feriados prolongados do mês de abril de 2006 em um resort. Desse modo, a primeira lacuna é preenchida, no nível intradiscursivo, com a palavra feriado. As duas lacunas seguintes apresentam, de acordo com Perini (1995), um problema em relação a uma descrição sintática coerente com a língua, que é o fato de admitir ou não elementos elípticos ou subentendidos na análise gramatical. Em um enunciado como Um feriado é pouco, dois ( ) é bom e três ( ) é 
demais!, deve haver uma identidade semântica entre a lacuna e um elemento presente no período, já que é preciso evitar a introdução aleatória de informações nos espaços vazios, ainda que elas sejam subentendidas. Podemos, portanto, admitir a presença de lacunas nos enunciados, no nível sintático, não preenchidas lexicalmente. Portanto, numa relação de paralelismo sintático, dois é bom e três é demais mantêm uma identidade semântica com a palavra presente no primeiro período, feriado, ao mesmo tempo em que conserva o enunciado original.

Ainda no nível intradiscursivo, um outro modificador do provérbio original é a locução adverbial Em abril, que inicia o enunciado e caracteriza um dêitico temporal (MAINGUENEAU, 2005). Esse texto publicitário foi publicado em 18/04/2006, entre uma sequência de feriados que aconteceram em 14/04, 21/04 e 01/05, explicitando, portanto, que essa expressão designa um tempo a partir do momento enunciativo: $E m$ abrilreferese a abril de 2006, permitindo que seu referente seja identificado em relação à situação enunciativa específica na qual se inscreve.

Essa construção, ainda, é ratificada pela estrutura linguística simétrica do enunciado original, que foi mantida no texto publicitário: Um - dois - três / pouco - bom - demais. Assim, podemos entender que Um feriado (14/04); dois feriados (21/04); três feriados (01/05) são, respectivamente, pouco, bom, demais.

O elemento modificador e incomum desse enunciado, entretanto, não é apenas sua natureza temporal ou o preenchimento de lacunas linguísticas presentes no provérbio original, mas a presença do ponto de exclamação que o finaliza: Em abril, um feriado é pouco, dois é bom e três é demais!. Ele reforça a natureza argumentativa do enunciado porque representa uma marca de modalidade que estabelece uma relação com o coenunciador por meio do ato de enunciação, já que o ponto de exclamação é empregado no final de enunciados com a intenção de, também, indicar um estado emocional como dor, surpresa, alegria, entre outros.

A novidade, nesse enunciado, é o fato de o ponto de exclamação representar uma ruptura no sentido original do provérbio. Passamos, então, nossas análises para o nível interdiscursivo. O reconhecimento dos provérbios pelos sujeitos dá-se porque esses enunciados fazem parte de uma memória discursiva, tendo um caráter estável porque mantêm sua materialidade linguística através do tempo. Ao ser proferido, o enunciador conta com ele para "introduzir uma situação particular em um quadro geral 
preestabelecido" (MAINGUENEAU, 2005, p. 171), esperando que o coenunciador estabeleça a relação entre a situação enunciativa e o provérbio. Desse modo, numa enunciação, o provérbio Um é pouco, dois é bom, três é demais estabelece sentidos previstos pela memória discursiva de ambos, enunciador e enunciatário.

O uso desse provérbio, invariavelmente, está associado a situações que se referem às relações pessoais, principalmente, relações amorosas. Na nossa cultura, um relacionamento amoroso ideal é composto por duas pessoas, portanto, ficar sozinho ( $\mathrm{Um}$ é pouco) ou ter uma pessoa a mais envolvida no relacionamento (três é demais) é fugir do ideário amoroso (dois é bom). Fixando-nos na última oração do enunciado proverbial, três é demais, entendemos o sentido do advérbio demais como algo que está sobrando; desse modo, no provérbio, em um relacionamento amoroso com três pessoas participantes, uma delas estará sobrando.

A compreensão desses sentidos dá-se pela memória, entendida como "estruturação da materialidade discursiva" (PÊCHEUX, 1999, p. 52), amparada na repetição e na regularização. Essa característica da memória, entretanto, permite o jogo da metáfora como outra possibilidade de articulação discursiva. Numa enunciação, o sujeito do discurso ocupa uma formação discursiva que representa, no discurso, uma formação ideológica: "os sentidos são sempre determinados ideologicamente" (ORLANDI, 1999 , p. 43). Isto é, o sujeito, ao proferir esse provérbio, pertence a uma formação discursiva que é atravessada por uma memória cujo dizer remete ao comportamento ideal nos relacionamentos amorosos.

O texto publicitário, por outro lado, reaviva outros sentidos a partir de sua materialidade, uma vez que a língua, para a $A D$, "é a condição de possibilidade do discurso" (ORLANDI, 1999, p. 22). O ponto de exclamação, colocado no final do enunciado, deriva sua significação. A expressão é demais! recupera um vocabulário atual, dos jovens, e tem como significado não mais o que sobra, mas aquilo que é muito bom. Considerando as condições de produção desse texto publicitário, o enunciador contou, primeiramente, com a colaboração do enunciatário, os leitores do jornal, no reconhecimento do provérbio, pois um discurso sempre se relaciona com outros que o sustentam, assim como para outros dizeres futuros. Ao interferir na materialidade do provérbio, o enunciador, pelo mecanismo de antecipação, que também faz parte das condições do discurso, colocou-se no lugar de seu interlocutor, prevendo os sentidos que 
seu dizer produziria. Nesse caso, então, enunciador e enunciatário reconhecem que $\mathrm{Em}$ abril, um feriado é pouco, dois é bom e três é muito bom.

Esse mecanismo de funcionamento discursivo é possível porque "Os sentidos não estão nas palavras delas mesmas, estão aquém e além delas" (ORLANDI, 1999, p. 42); é a posição ideológica que determina os sentidos. Assim, passamos de uma formação discursiva cujos sentidos apontam para um comportamento amoroso para outra em que o ideário é constituído por passeio, viagem, descanso. É pelo mecanismo de condições do discurso que essa passagem de uma formação discursiva para outra foi possível.

Segundo Maingueneau (2005), o poder de persuasão do discurso publicitário consiste em fazer com que o coenunciador se identifique com valores socialmente especificados por meio da fala do "fiador", que confere a si próprio uma identidade compatível com o mundo a ser construído em seu enunciado, que legitima sua maneira de dizer. Atualmente, o sujeito é caracterizado por um grau de mobilidade e flexibilidade e o crescimento das viagens e dos deslocamentos físicos aumentou a capacidade de se imaginar em novas situações, confrontando novas possibilidades. Isso é estimulado pela divulgação das experiências mediadas pelos meios de comunicação de massa; a mídia torna-se, assim, um "multiplicador de mobilidade", disponibilizando aos indivíduos um arsenal de experiências que permaneceriam encobertas, estimulando a imaginação e a necessidade da viagem física (THOMPSON, 1998, p. 167). O enunciador do texto publicitário parece saber dessa característica da modernidade, haja vista a articulação dos desejos do enunciatário no texto a partir de uma estratégia argumentativa que modifica a materialidade do provérbio.

A atualização do discurso mediante as marcas linguísticas organiza um determinado universo de sentido imposto tanto pelo ethos como pelas ideias que transmite: "uma maneira de dizer que remete a uma maneira de ser, à participação imaginária em uma experiência vivida" (MAINGUENEAU, 2005, p. 99). Assim, no enunciado - Em abril, um feriado é pouco, dois é bom e três é demais! - novos sentidos são instituídos, e a expressão é demais! organiza essa mudança a partir de uma gradação qualitativa: pouco / bom / muito bom. Sob o viés enunciativo, a movimentação dos planos discursivos possibilita uma cenografia que interpela o coeneunciador inserido em um quadro espácio-temporal definido ao mesmo tempo em que ele se reconhece em seu papel de consumidor, implicando um processo de "enlaçamento paradoxal" 
(MAINGUENEAU, 2005, p. 87): num primeiro momento, o reconhecimento do provérbio supõe uma situação de enunciação que se (des)constrói progressivamente na própria enunciação por intermédio da materialidade linguística.

\section{Análise 2}

Um outro exemplo de uso de provérbio pelo mass media é retirado, também, do jornal Folha de S. Paulo (12 maio 2006, p. A17), cujo texto traz: <Novo Z300i> As aparências não enganam.

Figura 2 : As aparências enganam

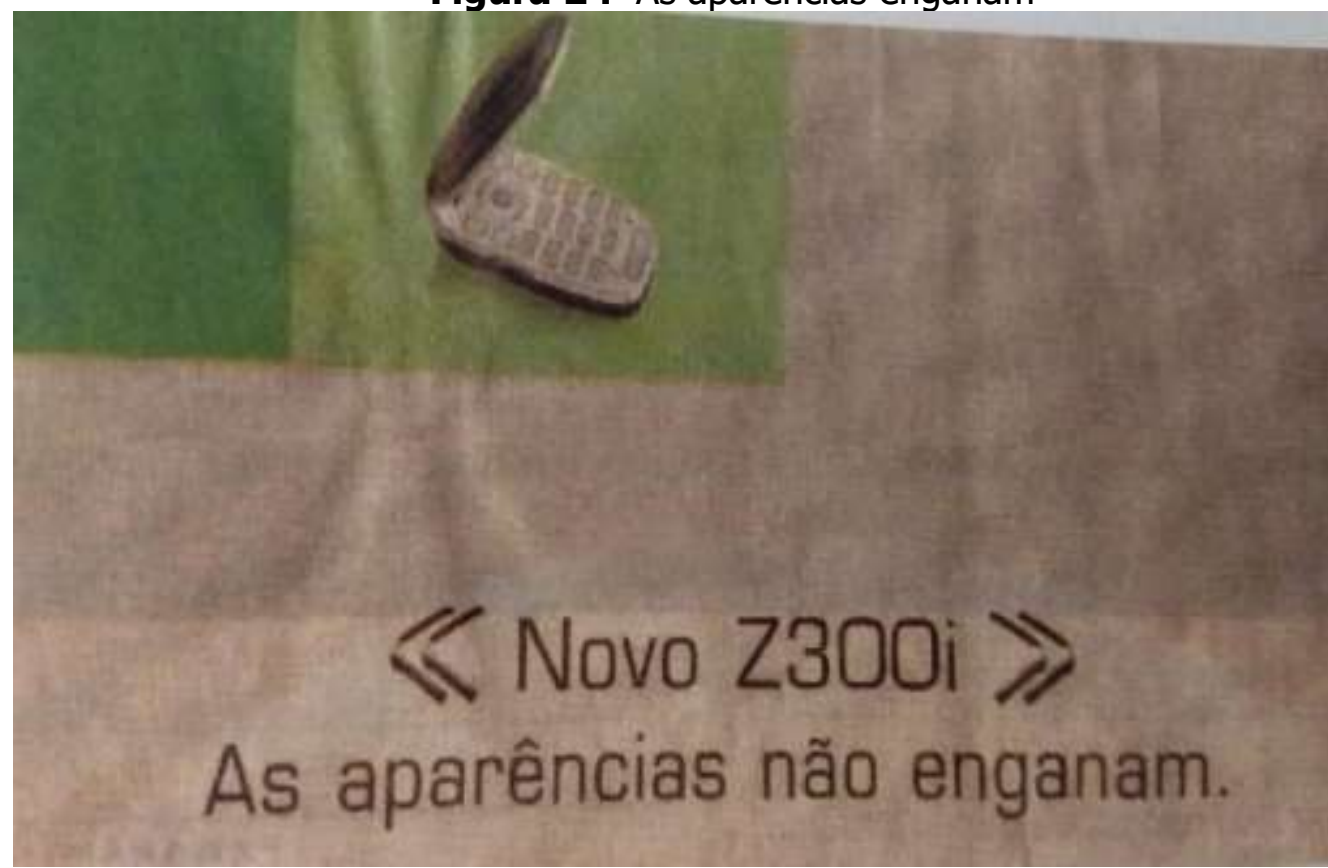

Fonte: Folha de S. Paulo (12 maio 2006)

Nesse caso, o provérbio sofre uma subversão na sua estrutura original, As aparências enganam. Novamente contamos com as condições de produção do discurso. A memória discursiva permite que se reconheça um texto sobre outro, é a relação entre o já-dito, o interdiscurso, com o que se está dizendo, o intradiscurso, que permite ao sentido constituir-se.

Nessa relação, é preciso considerar que todo funcionamento da linguagem se apoia nos processos de paráfrase e de polissemia. Os processos parafrásticos representam o mesmo dizer em formulações diferentes, é a memória significando. Nesse sentido, reconhecer o provérbio utilizado na propaganda é ativar a memória discursiva, trazer para a significação aquilo que está na memória do dizer.

Ao mesmo tempo, os processos polissêmicos permitem uma subversão do sentido, 
um deslocamento da significação. É nessa tensão entre o mesmo e o diferente que se constitui o discurso; é o espaço de movimentação dos sujeitos e dos sentidos. Para Orlandi (1999, p. 36), "[...] toda vez que falamos, ao tomar a palavra, produzimos uma mexida na rede de filiação dos sentidos, no entanto, falamos com palavras já ditas". Para a $A D$, diferencia-se a criatividade da produtividade. A produtividade é regida pela paráfrase e representa a reiteração do já-dito, do mesmo. A criatividade, por sua vez, rompe com os processos discursivos já estabilizados, dando lugar ao novo, ao diferente.

É nesse sentido que o texto publicitário utiliza o provérbio, rompendo com um sentido cristalizado pela condição inerente ao gênero discursivo a que ele pertence. Nesse caso, há uma clara subversão, o texto produzido não é o provérbio original, que sentencia uma constatação a respeito das relações sociais, apontando para uma desconfiança em relação ao visível, mas uma subversão que, por sua vez, contesta a autoridade da sabedoria popular por meio do recurso da negação.

Conforme Maingueneau (1997, p. 80), "a negação pode igualmente ser objeto de uma análise polifônica. Na realidade, é antiga a ideia de que é preciso distinguir, em um enunciado negativo, duas proposições, a saber, uma proposição primeira, e uma outra que a nega", funcionando como um reconhecimento do fato em si, ou seja, negar é reconhecer a existência do enunciado primeiro; nega-se aquele que gerou a negação, neste caso, a desconfiança do que é visível.

Apoiada nos trabalhos de Ducrot, para quem a negação é um "fato da língua inscrito na frase" (DUCROT, 1987, p. 201) em cuja enunciação faz aparecer o choque de duas atitudes antagônicas, atribuídas a dois enunciadores distintos, Indursky (1990, p. 119) chama de "relação polêmica" ao que se estabelece entre duas posições de sujeito que "representam FD antagônicas", o que significa que o sujeito refuta um elemento do saber de outra formação discursiva, ou seja, que the é exterior, rejeitando o que acredita estar fora dos sentidos autorizados pela sua FD. Assim, conforme o enunciado "As aparências não enganam", o sujeito rejeita o sentido indesejado, irrompendo, no intradiscurso, sob a modalidade de negação e afirmando o traço polifônico do discurso como marca da contradição.

Desse modo, não podemos considerar o provérbio como um enunciado totalmente neutro, mesmo implicando um mundo estabilizado, uma ordem imutável imposta por sua própria natureza e da sociedade, mas levar em conta o quadro envolvido em sua 
enunciação. Nesse particular, seguimos a postura teórica de Maingueneau (2008) acerca da $A D$, a qual predita não pensar as palavras independentemente do campo discursivo em que se encontram ou autorizam, nem considerar as coerções de um gênero específico, mas apreender o discurso na multiplicidade de seus planos.

No texto em pauta, o aspecto lúdico e original, próprio dos textos publicitários, coaduna-se com o tom sentencioso do provérbio. Ironicamente, para destacar as qualidades do produto anunciado, no caso um aparelho de telefone celular, o enunciador recorre apenas ao enunciado subvertido, sem acrescentar as qualidades do produto. Isso é uma indicação de que o tom sentencioso do provérbio e a autoridade que ele transmite ao enunciatário (leitores do jornal Folha de S. Paulo) são suficientes para autorizar o texto subvertido, mesmo que ele tenha sentido oposto ao provérbio, considerando como verdades incontestáveis as qualidades do produto, que estão visíveis, aparentes.

Para Bakhtin (1992, p. 271), "toda compreensão é prenhe de respostas", isto é, a comunicação discursiva implica uma atitude responsiva: o ouvinte concorda ou discorda, total ou parcialmente, com o significado do discurso. O próprio enunciador espera essa atitude em forma de concordância, participação, objeção ou execução. Além disso, o enunciador é também um "respondente", já que usa outros enunciados seus e de outrem que entram em correspondência com seu processo discursivo.

Na utilização de provérbios em textos propagandísticos escritos (como é o caso dos textos aqui analisados), o enunciador apropria-se de outros enunciados pertencentes a um gênero predominantemente oral que faz parte da cultura popular apoiado na certeza de que o enunciatário (consumidor) os reconhece e, mais do que isso, assume sua autoridade. Isso fica mais claro no caso deste segundo texto analisado, já que traz um enunciado subvertido pela oposição ao provérbio original. Ao recorrer a essa estratégia discursiva, o enunciador espera alcançar a aprovação do enunciatário e, consequentemente, convencê-lo a realizar o que foi proposto indiretamente no texto: a aquisição do produto anunciado, manifestando uma atitude responsiva.

\section{Considerações finais}

É possível verificar que tanto a persuasão quanto a interpretação dos sujeitos podem realizar-se no e pelo discurso publicitário. E maior será a eficácia se os sujeitos enunciador e enunciatário partilharem da mesma formação discursiva: o discurso parecerá mais verdadeiro quanto mais o destinatário identificar e conseguir comprovar, 
por meio das performances apresentadas em forma de simulacro, suas convicções e verdades íntimas.

Essa relação só é possível porque, no processo de produção do discurso em questão, o enunciador coloca-se no lugar do enunciatário, antecipando o sentido que suas palavras produzirão. É o jogo de imagens que designa as formações discursivas, permitindo o mecanismo de antecipação. 0 texto publicitário, portanto, movimenta sentidos porque os sujeitos pertencem a uma formação discursiva que "determina o que pode e deve ser dito" (ORLANDI, 1999, p. 43) e cujos dizeres estão relacionados com as condições de produção, com a memória e com o jogo da metáfora e da paráfrase.

O discurso publicitário, desse modo, faz a mediação entre o objeto a ser consumido e os consumidores, mostrando na e pela linguagem que possuir o que é oferecido é o mesmo que alcançar a felicidade: "sem a auréola que a publicidade the confere [ao objeto], seriam apenas bens de consumo, mas, unificados, personalizados, adquirem atributos da condição humana" (CARVALHO, 1998, p. 12). A linguagem da publicidade dissimula o discurso ideológico e é pelas práticas discursivas que se constituem e se cristalizam os efeitos de sentido, ou seja, o sentido é construído na relação entre quem o produz, quem o lê e com outros sentidos instaurados em outros enunciados. Podemos dizer, então, que o sentido não existe em si, mas é determinado pelas posições ideológicas colocadas em jogo no processo sócio-histórico em que as palavras são produzidas no bojo dos anúncios publicitários.

Nossas análises evidenciam que os provérbios, subvertidos ou não em seu sentido original, participam como estratégias discursivas de convencimento, já que transmitem a autoridade da voz do povo, via mídia impressa. Verificamos, nos textos analisados, que os discursos transversos articulados são recortados em unidades significantes, constituindo-se em memória discursiva, que é formada por aqueles sentidos possíveis de se tornarem presentes no acontecimento da linguagem: um discurso (publicitário) aponta para outros (consumista, capitalista, moderno, etc.) que o sustentam, assim como para dizeres futuros.

É certo que somente a pluralidade de perspectivas de enunciação pode configurar o discurso publicitário como um campo vastíssimo e representativo da diversidade social. Revelar esse funcionamento discursivo é imprescindível para os estudos de jornalismo, de propaganda, de comunicação, entre outros. 


\section{Referências}

BAKHTIN, M. Estética da criação verbal. Tradução Paulo Bezerra. São Paulo: Martins Fontes, 2003.

BAKHTIN, M. Marxismo e filosofia da linguagem. Tradução Michel Lahud e Yara F. Vieira. São Paulo: Hucitec, 1992.

CARVALHO, N. Publicidade: a linguagem da sedução. 2. ed. São Paulo: Editora Ática, 1998.

CHARAUDEAU, P.; MAINGUENEAU, D. Dictionnaire d'Analyse du discours. Paris: Seuil, 2002.

DE CERTEAU, M. $A$ invenção do cotidiano: $1^{\circ}$ artes do fazer. 11. ed. Petrópolis: Vozes, 2005.

DUCROT, O. O dizer e o dito. Campinas: Pontes, 1987.

INDURSKY, F. Polêmica e denegação: dois funcionamentos discursivos da negação. Cadernos de Estudos Linguísticos, Campinas, v. 19, p. 117-122, 1990.

LANDOWSKI, E. A sociedade refletida: ensaios de sociossemiótica. Tradução Eduardo Brandão. São Paulo: EDUC/Pontes, 1992.

MAINGUENEAU, D. Análise de textos de comunicação. 4. ed. São Paulo: Cortez, 2005.

MAINGUENEAU, D. Cenas da Enunciação. Curitiba: Criar Edições, 2006.

MAINGUENEAU, D. Discurso e análise do discurso. In: SIGNORINI, I. (org.). [Re]discutir texto, gênero e discurso. São Paulo: Parábola Editorial, 2008. p. 135-156.

MAINGUENEAU, D. Novas tendências em análise o discurso. Tradução Freda Indursky. Campinas: Pontes, 1997.

OBELKEVICH, J. Provérbios e história social. In: BURKE, P.; PORTER, R. (org.). História social da linguagem. São Paulo: Cambridge EdUnesp, 1997. p. 43-81.

ORLANDI, E. P. Análise do discurso: princípios e procedimentos. Campinas: Pontes, 1999.

ORLANDI, E. P. Interpretação: autoria, leitura e efeitos do trabalho simbólico.

Petrópolis: Vozes, 2004.

PÊCHEUX, M. Análise do discurso: três épocas (1983) In: GADET, F.; HAK, T. (org.). Por uma análise automática do discurso: uma introdução à obra de Michel Pêcheux.

Tradução Péricles Cunha. Campinas: Ed. UNICAMP, 1990.

PÊCHEUX, M. Papel da memória. In: ACHARD, P. et.al. Papel da memória. Tradução 
MORAES, A. L. F.

José Horta Nunes. Campinas: Pontes, 1999. p. 49-57.

PERINI, M. Para uma nova gramática de português. 8. ed. São Paulo: Ática, 1995.

THOMPSON, J. B. A mídia e a modernidade: uma teoria social da mídia. Tradução Wagner de Oliveira Brandão. Petrópolis: Vozes, 1998.

Submetido em: 06 mai. 2021. Aceito em: 14 jul. 2021. 